Ciência e Natura, v. 37 Part 2 jun. 2015, p.61-68

\title{
Issues on Interpreting
}

\author{
Roghiyeh Asgari
}

MA Graduated in Translation Studies, Faculty of Foreign Languages, Department of English, IAUCTB, Tehran, Iran

\begin{abstract}
Interpreting is an ancient human practice which clearly predates the invention of writing and translation. Interpreting has existed for a long time. Whenever people met other people who had no common language they had to make do with sing language or find someone who speak both languages (Pochhacker, 2004). Interpreting is a form of translation in which a first and final rendition in another language is produced on the basis of a one-time presentation of an utterance in a source language (ibid). This paper is intended to provide some crucial features presented in interpreting; the quality of which directly affect the quality of interpreting.
\end{abstract}

Keywords: Interpreting, translation, language 


\section{Introduction}

According to Pochhacker (2004), within the conceptual structure of translation, interpreting can be distinguished from other types of translational activity most succinctly by its immediacy. In principle, interpreting is performed 'here and now' for the benefit of people who want to engage in communication across barriers of language and culture. Riccardi (2002), states that interpreting, understood as the mental process and communicative act of reproducing orally in a target language what a speaker is expressing in a source language, has often been regarded by translation scholars as phenomena which can be studied within the framework of and by means of translation science, translation studies, or translatology. As cited in Pochhacker (2004), Kade's opinion is that in contrast to common usage as reflected in most dictionaries, interpreting need not necessarily be equated with 'oral translation', or more precisely, with the 'oral rendering of the spoken messages'. Doing so would exclude interpreting in signed (rather than spoken) languages. Instead, by elaborating on the feature of immediacy, one can distinguish interpreting from other forms of translation without resorting to the dichotomy of oral vs. written. Janzen (2005), continues that interpreting for people who don't share the same language involves understanding the ideas of one person inferred from one linguistic structure and re-constructing them into another linguistic structure, that of the language used by those intended to receive the interpreted message. Seleskovitch (1978) goes so far as to say that the actual wording of a source message is largely immaterial, that interpreters must immediately discard the original wording and retain only the ideas, or sense, underlying the speaker's text. One reason for this claim is that word meaning can be variable -a word can often mean one thing in one context and something else in another, so that an interpreter cannot depend on what any word might mean when it is isolated out of a specific context.
Of course, it should be mentioned that in English the term 'interpretation' is often used instead of 'interpreting'; however, some theorists emphasizes that the use of former as the synonym of the later should be prevented (Shuttleworth and Cowie, 1997).

\section{A Brief History of Interpreting}

Interpreting is an ancient human practice which clearly predates the invention of writing and translation. The English word 'interpreter' is derived from Latin 'interpres' means a person explaining what is obscure (Pochhacker, 2004). Baker (1998) quotes that interpreting as an official or professional function seems to have been in existence since very early time; some studies have indicated its use in ancient Egypt.

To find the origin of interpreting, Gross (as cited in Soleymani 2011) goes back as far as birth of language itself. He notes that just as many meanings of the Greek and Latin words for interpreter provided us with a window onto prehistory, so what we now know about prehistory also provides us with a window opening directly onto the origins of language.

He claims that it is clear that Hermes is the god of translation and interpreting; although some European translators have claimed that St Jerome is the patron saint of translation. Gross continues that Hermes was par excellence the god of interpreting, of quick-wittedness, of wily improvisation, while translation, like writing itself, was a later development. Hermes was considered as a divine messenger. He was also in charge of commerce and travel which is related to interpreting (ibid).

For the word Hermes, Socrates (as cited in Soleymani, 2011) says that: "I should imagine that the name Hermes has to do with speech, and signifies that he is the interpreter (Hermeneus), or messenger, or thief, or lair, or bargainer; all that sort of thing has a great deal to do with language."

According to Soleymani (2011), the ancient Greek word for interpreter is Hermeneus which means mediator, go-between, deal-broker and marriage-broker. The verb Hermeneuo means 
interpreting foreign language, translating, explaining, expounding, putting into word, expressing, describing, and writing about. In those old days, it was the travelers and tradesmen who were transferring thoughts and ideas from cultures to cultures and places to places. It all shows that interpreters must have existed during prehistory - the period before writing was invented.

\section{Interpreting vs. Translating}

"It should not surprise us to learn that many people including the learned of the field of translation always misuse the two terms 'interpreting' versus 'translation' and try to use them interchangeably." (Miremadi, 2005:179)

Despite being used interchangeably, interpretation and translation are not synonymous, but refer, respectively, to the spoken and written transference of meaning between two languages. Interpreting occurs in real time, in the presence -physical, televised, or telephonic- of the parties for whom the interpreters renders an interpretation. Translation is the transference of meaning from text to text (written, recorded, sign), with the translator having time and access to resources (dictionaries, glossaries, etc.) to produce a faithful, true, and accurate document or verbal artifact (Wikipedia, para. 5). Moreover, Seleskovitch (1978) suggests that in interpreting community, those who first reflected upon their activity agreed that interpreting was quite different from translation. They were convinced that in interpreting one had to be guided by the sense and not by the words; whereas translators had to focus on the wording of a text.

As cited in Neshati (2007), Ronald argues that, due to its nature, translation is slow, changeable, re modifiable, and not necessarily quick. In other words, the translator has a great deal of time to readjust his rendering repeatedly without feeling any necessity in rush. On the other hand, the interpreter cannot be slow, has no option to make changes in words, structures, and styles, and in the circumstances where he/she is rendering texts, being quick is a must. The only advantage that interpreter enjoys, whereas the translator lacks it, is the way he/she benefits from the gestures of the speaker. Thus, nonverbal factors showing happiness, anger hatred, seriousness, easy-going mood, flexibility and inflexibility in positions help the interpreter to asses more information while he/she is interpreting.

Pochhacker (1995) points to the similarities between interpreting and translation. $\mathrm{He}$ conceptualizes the two activates through the notion of skopos. He sees interpreting and translation as 'twines' and brings out the similarities between the two activities: both 'seeks to achieve a communicative purpose (i.e. skopos rule).'

However, Kopezynski (cited in Miremadi, 2001) summarizes the differences between interpreting and translating as follow:

A. In translation,

1. The author, the translator, and the receptors enjoy three different contexts of situation.

2. As usually carried out, the translator has no close contacts with the author or receptors.

3. The translator has always the chance to receive his/her translation and to modify it based on the readers' reactions.

4. The encoding and decoding of the message are carried out in written forms.

5. The message carried over is a permanent message not usually changed and modified by the author.

B. In interpretation,

1. There exist the same contact of situation for the speaker who sends the message, the interpreter who transfuses it, and the receptors who receive the message.

2. The interpreter, relying on the speaker or/and the receptors has only the chance for quick instantaneous readjustments of the interpretation.

3 . The message enjoys a transient character.

4. The encoding and decoding of the message is carried out in the spoken form.

According to Riccardi (2002), although both translators and interpreters are cultural mediators who may to a greater or lesser extent influence the way in which a ST is perceived in the target language, the most important differences between translation and interpretation regard the conditions under which they are carried out, such as time and environment, the cultural situation, the texts both ST and TT - and the subjects. 
As cited in Amini (2011), Mahmoodzadeh lists the characteristics of the two disciplines as follow:

1. The translated text is smooth and fluent.

2. The translated text is structurally TL oriented.

3. The translated text is lexically TL oriented.

4. The interpreted version is structurally SL oriented.

5. The interpreted version is lexically SL oriented.

6. The translated text is more accurate than the interpreted version.

7. The translated text is more coherent and comprehensible than the interpreted version.

8. The translated text is sometimes longer than the original and the interpreted version is shorter.

Furthermore, Rostami (2009) states that the translators activity is more like that of a writer's, while the interpreter's performance is more like that of an actor's. A good translator will spend much time searching for the correct technical term or the right choice of words, but a good interpreter must immediately come up with a satisfactory paraphrase or a rough equivalent if le mot juste does not come to mind, in order not to keep the audience waiting.

\section{Some Important Issues on Interpreting}

\subsection{Knowledge}

For a practice or occupation to be acknowledged as a profession, it must be perceived to rest on a complex body of knowledge, mastery of which can only be acquired by specialized training (Pochhacker, 2004). According to Janzen (as cited in Mobaraki, 2011), there are two aspects to an interpreter's knowledge of language: intuitive knowledge and knowledge gained by careful study. These two aspects are not mutually exclusive. Conscious effort in studying the structure and meaning of language can reinforce intuitive knowledge, and sometimes challenge it. He believes that intuitive knowledge of language is critical because the interpreter's attention must be shared among several taxing efforts: taking in the source text, analysis, and production of the target. Gile (1995) adds that in interpreting, the knowledge of acquisition process must be completed to a large extent before interpreting begins; while in translation it takes place on-line. In other words, before starting their works, interpreters should acquire as much specific knowledge as possible, whereas translators can gain knowledge while translating their text.

\subsection{Powerful Listening}

Listening is the first step to be able to communicate with each other. An interpreter needs a good listening ability to be able to interpret. Listening ability is one of the basic and important skills that an interpreter should have. Because an interpreter will have a lot of difficulties in comprehending the message of source language that he/she listened, a good listening ability will help him/her to avoid misunderstanding of source difficult pronounced words or even misunderstanding of spontaneous gestures, anecdotes during a speaker delivers his/her speech (Resmiyanti, 2008 ).

Based on Afsari's (2012) opinion, listening can help interpreters to adapt themselves to the speaker's delivery to overcome both external and internal distractions, to get the gist of the message, and to formulate their translations.

\subsection{Discourse and Meaning}

Mollanazar (1997, p. 3) emphasizes that: "discourse encompasses all the elements relevant in communication: text (here means speech) and context. A text is explicit realization of the discourse. [Language and texts are considered to be realizations of sociocultural messages and power relations; the discourse. (Munday, 2001)] .

But the author/speaker intends the reader/hearer to use certain contextual assumptions, such as relevant elements of situation or some shared background knowledge to interpret the whole message."

Janzen (2005) adds that the interactions of speakers and of signers are not self-contained units, completely meaningful without reference to the communicators of their surroundings. Thus language cannot be seen as an entirely objective thing. Rather, an intention conveyed by 
linguistic means (i.e. a message) can only be correctly apprehended in relation to its context.

Seleskovitch (1978) argues that interpreting should not be considered to just be the oral translation of words. What the interpreter is expected to do is to uncover meaning and to make it explicit for others. She adds that interpretation is more like painting than photography. Photography reproduces words without attempting to explain their meaning. Painting seeks to discover a meaning, to convey a message and reflects the object as seen through the eyes of the painter. Therefore, the interpreter must 'apprehend' the source language of the massage to understand the meaning. The meaning of a message can only be apprehended when effort is expended in considering possible meanings and intentions; many times even by comparing what is being said to what is not being said.

\subsection{Memory}

The modern conception of memory for the mental representation of sensory input emerged in the mid-twentieth century, when psychologists developed the hypothesis of a temporary storage system distinct from a more durable form of 'storage' based on networks of neurochemical traces or activation patterns. Various models of memory allowing for 'shortterm' and 'long-term' storage have since been proposed, and short-term memory resources, generally referred to as 'working memory', have emerged as a central concern in researches on language and cognitive processing (Pochhacker, 2004). Of course, an excellent memory is an important trait for any good interpreter. As cited in Mobaraki (2011), Janzen argues that both long term memory and short term memory (or working memory) is critical in the field of interpreting. Short-term memory capacity is central to both simultaneous and consecutive interpreting, although in somewhat different ways. Information from the source language speech must be retained even if the exact form it takes is rapidly forgotten.

According to Gile (1995), during interpretation, short-term memory operations (up to a few seconds) occur continuously. Its operations fall under the category of nonautomatic operations because they include the storage of information for later use. He refers to these operations as the short-term Memory Effect which is pushed and pulled among others (the Listening and Analysis Effort and Production Effort). Janzen (as cited in Mobaraki, 2011) continues that short-term memory is critical for recalling immediate aspects of the source message, and long-term memory gives the interpreter access to the source and target language lexicon, grammar and discourse structure information.

\subsection{Note-taking}

One of the essential parts of an interpreter's work by different researches is described as: understanding, analysis, and re-expression. Notes are an aid to enhance the work done on the basis of these three components, not being an aid in themselves, but a means to an end. The main use of notes is to relieve memory. Although an interpreter may have understood the main ideas of a speech, it is almost impossible for him/her to recall all the elements of a five minutes speech; particularly if it contains numbers, names, lists, since such elements cannot be recalled on the basis of analysis and logic (Miremadi, 2001).

He also argues that it is a fact that, in writing down what a speaker says, one has to be selective. Not all words can be written down equal in space with those of the speaker. According to Amini (2011), some linguists argue that selectivity should be confined to prominent words, that is, those words which play key roles in sentence semantics. Thus, they believe that a consecutive interpreter should jot down only those words which can be later used in recalling sentences. In note-taking, the interpreter should as much abbreviate forms as possible, providing that he/she can read them later; in fact, the interpreters are to highlight the distinctive graphic features.

Moreover, Asli (2006) declares that notes are useful in terms of "noetic content" which is nonlinguistic but pragmatics. The loss of pragmatic meaning means not understanding relevantly and therefore uttering nonsense. Briefly, what is essential is bringing deep meaning and sense of the message to the note, is not writing every word and using it as a decisive mean for 
recalling, but linking and expressing the speaker's utterance coherently.

\subsection{Time, the Biggest Restriction in Interpreting}

As cited in Riccardi (2002), Kade points out that translation is characterized by the fixed and stable nature of both the source and the target text (ST, TT). A translation may be carried out repeatedly, it may be corrected and checked over and over again; whereas in interpretation the ST is expressed only once and mostly orally and the TT can be controlled only partially and can hardly be corrected because of the time pressure conditioning interpretation, especially in the simultaneous form. Similarly, Mahmoodzadeh (2003, p. 47) mentions that:

"As far as conduct is concerned, there are privileges the translator enjoys, but the interpreter is deprived of. These privileges may be listed as follows:

1. The possibility of reading the source language text as many times as the translator deems necessary.

2. The possibility of analyzing the source language text.

3. Access to all kinds of sources and references.

4. The possibility of restructuring."

He concludes that: "time is the only enemy the interpreter cannot thoroughly defeat." (ibid, p. 53)

In interpretation, in addition, Gile (1995) states that much of the specific knowledge required for task performance is acquired before beginning the task, because there is simply not enough time while interpreting. In translation the situation is totally different, in that specific knowledge is acquired during the task as the requirement arises. This allows the translator to optimize efforts, none of which are wasted on information not directly used for the task.

\subsection{Anticipation}

Gile (1995) defines anticipation as 'the target language production by the interpreter of a (sign of) word (s) before (or simultaneous with) the speaker's production of the corresponding (string of) words.' According to Sha'bani (2005), anticipation is simply defined as the listener's normal reaction to the linguistic and extra linguistic ambiguities throughout listening.

As cited in Vandepitte (2005), Lederer introduces different types of anticipation. Firstly, she recognizes "anticipations based on language prediction" (which have later been referred to as linguistic anticipation) on the one hand, and "anticipations based on sense expectation" (which have later been called extra linguistic anticipation). These two types of anticipation actually involve the activity of different modules in the mind. With the former, a particular linguistic item (e.g. the second element of a collocation) is retrieved by means of linguistic knowledge only. Any native speaker of English, for instance, is able to continue the utterance

She was green with ...

with the word envy. Sometimes, however, one word may occur in different collocations, for instance, to hold off. An utterance like

They held off ...

cannot be finished with the linguistic information present only; one needs additional (situational or contextual) pragmatic information. If that information is present, the second type of anticipation can be produced. For example, as soon as one knows they refers to the general and a few high officers, one may think in terms of holding off something like 'the enemy's attack'. If, on the other hand, they refers to committee members, one may continue the utterance with 'their decision'.

Secondly, Lederer also makes a distinction between anticipation proper and freewheeling: in the former instance, the interpreter's production comes before speaker's production; in the latter, it comes more or less at the same time as the speaker's production.

As a conclusion, interpreters would be better to rely on their anticipatory and predicting ability to save the time.

\subsection{Speaking and Speed of Delivery}

The speed rate in speaking is the number of words or syllables that one utters in a fixed period of time (Barik, 1973). Bowen (as mentioned in Rostami, 2009) believes that the number of words uttered in a minute varies from 120 to 150 words per minute. Exceptional cases 
have been reported when speakers have produced more than 220 words per minute.

According to Amini (2011), speed of interpreting is related to some different factors including speed of input, source-text complexity, strategies used by the interpreter, interpreter's knowledge regarding source or target language, and also the topic under discussion, intonation patterns, and some other factors.

Viaggio (2006) puts force that the ability to speak and produce adequate speech act, is the interpreter's presence or representation that equals with the textual competence in writing translation. The interpreter's competence is his/her ability in correct expressing, good reproduction and in good use of different registers, relevantly.

\subsection{Pronunciation}

Based on the opinion of Morley (1991), the goal of pronunciation is developing functional intelligibility, communicability, increased selfconfidence, and the development of speech abilities. He believes that intelligible pronunciation is an essential component of communication competence.

In interpreting, says Elson (1992), pronunciation is clearly a central factor in interpreters' success in making themselves understood. Similarly, Mahmoodzadeh (2006, p.41) highlights that: "One of the significant features attributed to professional interpreters is that they are able to understand all the variations of their working languages, but at the same time they have a 'standard' pronunciation with any of the internationally recognized accents so that they can easily be understood by all the speakers of these languages, whether native or non-native. In addition to having a standard pronunciation, each and every one of the interpreters should be able to pronounce the words clearly, and this is of great significance."

\section{Conclusion}

The distinction between translation and interpreting is a necessary one - they are very different activities. In translation, neither authors of source texts nor addressees of target texts are usually present so no over interaction or direct feedback can take place. In the interpreting situation, on the other hand, both author and addressees are usually present, and interaction and feedback may occur. Since the new text emerges chunk by chunk and do not 'stay permanently with the interpreter (or the addressees)', it is only controllable and correctible by the interpreter to a limited extent (House, 2009). The interpreter's voice may then become to a greater or lesser extent 'a carrier without substance of its own, a virtually transparent vehicle' (Hermans, 1996). This act of transparency includes some elements the rendering of which are diachronic.

\section{References}

Afsari, J. (2012). Using communication strategies in oral translation and listening practice influence on the use of communication strategies in oral translation. (Unpublished MA dissertation). Islamic Azad University of Central Tehran Branch, Iran.

Amini, M. (2011). On the relationship between the interpreters' speed of speaking in their mother tongue (i.e. Persian) and their speed of consecutive interpreting (i.e. from English to Persian). (Unpublished MA dissertation). Islamic Azad University of Central Tehran Branch, Iran.

Asli, S. (2006). Note-taking strategy and the consecutive interpreting quality. (Unpublished MA dissertation). Islamic Azad University of Central Tehran Branch, Iran.

Baker, M. (1998). Routledge encyclopedia of translation studies. London: Routledge.

Barik, H.C. (1973). Simultaneous interpretation: Temporal and quantitative data. Language and Speech, 16 (3): 237- 270.

Elson, N. (1992). Teaching American English pronunciation. London: Oxford University Press.

Gile, D. (1995). Basic concepts and models for interpreter and translator training. USA: Benjamins.

Hermans, T. (1996). The translator's voice in translated narative. Target, 1 (8), 23-48.

House, J. (2009). Translation. New York: Oxford University Press. 
Janzen, T. (2005). Interpretation and language use: ASL and English. Amsterdam: Benjamins.

Mahmoodzadeh, K. (2003). Time: The major difference between translating and interpreting. Translation Studies Quarterly, $1(1), 45-54$.

Mahmoodzadeh, K. (2006). Why Do you have to mumble? A glance at the performance of interpreter. Translation Studies Quarterly, 4(15), 33-43.

Miremadi, S. A. (2001). Theories of Translation and Interpretation. Tehran, SAMT.

Miremadi, S. A. (2005). Theoretical foundations and principles of translation. Tehran: SAMT.

Mobaraki, M. (2011). Interpretation. Tehran: Rahnama Press.

Mollanazar, H. (1997). Principles and methodology of translation. Tehran: SAMT.

Morley, J. (1991). The pronunciation component in teaching English to speakers of other languages. TESOL Quarterly, 25(1), 51-74.

Munday, J. (2001). Introducing translation studies. London: Routledge.

Neshati, M. (2007). On the relationship between the speed of speaking in Farsi and the quality of consecutive interpreting from English to Farsi among undergraduate students of English translation. (Unpublished M.A. dissertation). Islamic Azad University of Central Tehran Branch, Iran.

Pochhacker, F. (1995). "simultaneous interpreting: A functionalist perspective". Hermes, Journal of Linguistics, 14(3), 31-53.

Pochhacker, F. (2004). Introducing interpreting studies. London: Routledge.

Resmiyanti, R. (2008). The correlation between listening skill and interpreting ability of the second grade students at MTS Sadarmanah Cimahi. ABC of Translation, 3(6). Retrieved from:

http://www.eng.helsinki.translation.ckl.56/

Riccardi, A. (2002). Translation studies: Perspectives on an emerging discipline. New York: Cambridge University Press.
Rostami, M. (2009). On the relationship between interpreters' speed of speaking in their second language and the quality of their consecutive interpreting. (Unpublished MA dissertation). Islamic Azad University of Central Tehran Branch, Iran.

Seleskovitch, D. (1978). Interpreting for international conferences. Washington D.C.: Pen and Booth Publishers.

Sha'bani, K. (2005). Anticipation strategy and simultaneous interpreting. Translation Studies Quarterly, 2 (7 \& 8), 9- 32.

Shuttleworth, M. and Cowie, M. (1997). Dictionary of translation studies. Ney York: Oxford University Press.

Soleymani, M. (2011). The relationship between extroversion/introversion and the quality of consecutive translation. (Unpublished M.A. dissertation). Islamic Azad University of Central Tehran Branch, Iran.

Vandepitte, S. (2005). Anticipation in conference interpreting: A cognitive process. Revista Alicantina de Estudios Inglese 14 (2001), 323335.

Viaggio, S. (2006). Speech, communication, translation and mediation: a general theory of interlingual mediation. Berlin: Frank and Timme Verlag.

Wikipedia. Translation. Retrieved from http:// http://en.wikipedia.org/wiki/translation. 